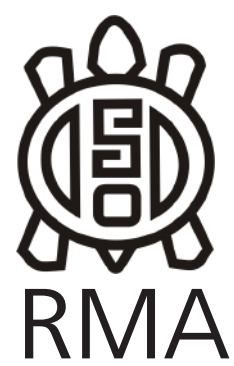

Museología

\section{El público y el patrimonio arqueológico. El caso de la comunidad de Tres Arroyos en relación con el sitio "Arroyo Seco 2" y la muestra del Museo Municipal "José A. Mulazzi"}

\author{
María Eugenia Conforti*
}

* CONICET, INCUAPA, PATRIMONIA. Facultad de Ciencias Sociales, Universidad Nacional del Centro de la Provincia de Buenos Aires, Olavarría, Argentina. E-mail: meconfor@soc.unicen.edu.ar

\begin{abstract}
Resumen
El propósito de este trabajo es presentar y analizar la opinión del público en relación con la arqueología y el patrimonio arqueológico. De este modo, se espera contribuir a la discusión del patrimonio arqueológico en relación con su comunicación en ámbitos de educación no formal. En este sentido, se considera a los museos como espacios de educación (no formal) y de comunicación. Para abordar esta temática, se toma como ejemplo el caso de la comunidad de Tres Arroyos, ubicada en la provincia de Buenos Aires, Argentina, en relación con el sitio arqueológico de renombre mundial "Arroyo Seco 2" y la exhibición que sobre el mismo se presenta en el Museo Municipal "José A. Mulazzi". Como herramienta metodológica, se utiliza la encuesta efectuada al público visitante de la muestra en el museo.
\end{abstract}

Palabras Clave: Público; patrimonio arqueológico; comunicación; educación no formal; museos.

The public and the archaeological heritage. The case of Tres Arroyos community in relation to Arroyo Seco 2 site and the exhibition housed in the local "José A. Mulazzi" Municipal Museum

\begin{abstract}
This paper intends analyzing public opinion on archeology and archaeological heritage. Thus, we expect to contribute to the discussion of archaeological heritage in relation to its communication in non-formal education contextual settings (e.g. museums). To address this issue, we selected Tres Arroyos, city located in the province of Buenos Aires, Argentina, in connection with Arroyo Seco 2, world-renowned archaeological site, and the related exhibition housed in the local José A. Mulazzi Municipal Museum. A survey was adopted as a methodological resource to find out visitors' opinions of the exhibition at the museum.
\end{abstract}

Keywords: public; archaeological heritage; communication; non-formal education, museum.

Desde hace aproximadamente dos décadas, desde la arqueología pública (Hewison 1987; Walsh 1992; Cooper et al. 1995, etc.) se comenzó a analizar la necesidad de conocer la visión del público (Stone 1989; Merriman 1991, etc.). En Argentina, sin embargo, esta es una temática relativamente reciente (e.g., Acosta et al. 1996; Cortegosso y Chiavazza 2003; Ferraro 2000; Tapia 1998) y escasamente analizada, aunque resulta esencial conocer la manera en que un sitio arqueológico es percibido por el público en general y, en particular, por la comunidad local (Endere 2004). Por ello, puede afirmarse que, para que una exhibición adquiera sentido, necesariamente debe interactuar con el público. Conocer la forma en que la interpretación ${ }^{1}$ del patrimonio arqueológico efectuada es percibida por la comunidad contribuye, además, a entender el contexto en el cual el museo está inserto. Tal

\footnotetext{
1. "Interpretación" es aquella explicación o presentación pública, cuidadosamente planeada, que aborda el completo significado de un lugar con patrimonio cultural (Carta de Ename 2004).
}

como lo postula la Carta de ENAME para la interpretación de lugares pertenecientes al patrimonio cultural (propuesta para su adopción formal por ICOMOS), la interpretación de un lugar con valor patrimonial entraña un desafío constante que requiere de una labor continua de investigación, formación y evaluación. El programa de interpretación y su infraestructura se articularán de forma tal que permitan su continua actualización, ampliación y revisión. En este sentido, es necesario disponer de programas de evaluación y seguimiento continuos para apreciar la reacción de los visitantes ante los programas de interpretación, así como para valorar el impacto y las repercusiones que esta actividad genera, tanto en el entramado histórico de cada lugar como en sus habitantes (Carta de Ename, en ICOMOS 2004).

Para comprender los procesos que han experimentado tanto el sitio arqueológico "Arroyo Seco 2" (en adelante AS2) como el Museo Municipal "José A. Mulazzi" de la ciudad de Tres Arroyos, se presenta previamente una breve reseña de ambos. 


\section{El sitio Arroyo Seco 2}

La localidad arqueológica Arroyo Seco fue descubierta en la década de 1970 por amateurs, se encuentra a $5 \mathrm{~km}$ de la ciudad de Tres Arroyos, provincia de Buenos Aires, y está comprendida por tres sitios, los cuales se encuentran próximos al Primer Brazo de los Tres Arroyos o Arroyo Seco (Fidalgo et al. 1986). El sitio 1 se ubica sobre la margen izquierda del arroyo, a 200 metros al sur de las instalaciones del Tiro Federal de Tres Arroyos, fue excavado primero por aficionados y luego por arqueólogos, pero las condiciones en las que se encontraba impidieron continuar. No existe, hasta el presente, ninguna estimación cronológica para este sitio (Politis 1988). El sitio 2 fue excavado en 1977 bajo la supervisión científica de Alberto Rex González, y en 1979 fue reexcavado por los arqueólogos Gustavo Politis y Luis Meo Guzmán, de la Universidad de La Plata (Endere 2004); en él se realizaron la mayoría de las excavaciones sistemáticas por la variedad, cantidad y óptimas condiciones de conservación de los materiales. Aún hoy se sigue trabajando sobre el sitio 2. El sitio 3 está ubicado frente al sitio 2 y se encuentra separado de este por la pequeña laguna temporaria (Fidalgo et al. 1986); no se realizaron excavaciones sistemáticas sino sólo recolecciones superficiales.

En el sitio arqueológico AS2 existe abundante evidencia de actividades diversas y de enterratorios en un área de ocupación utilizada por grupos cazadores-recolectores desde el Pleistoceno final $^{2}$ u Holoceno temprano ${ }^{3}$ hasta tiempos históricos (ver Politis 1984, 1989; Politis et al. 1987, 1988, 1992; Barrientos 1997; Gómez et al. 1999; Politis y Madrid 2001; Barrientos y Pérez 2002, etc.). En 1986, AS2 fue declarado lugar histórico por el municipio, y encomendado su estudio al Dr. Politis (Decreto 343/86, ver también Ordenanza 2682/87). En 1990, la Municipalidad cedió por quince años el sitio a la Universidad Nacional del Centro de la Provincia de Buenos Aires para crear la Escuela de Campo de Arqueología "Gesué Noseda" de la Facultad de Ciencias Sociales (Ordenanza 3043/90). Este convenio se renovó en el año 2005 y aún continúa vigente. Hasta la actualidad, se han excavado aproximadamente 250 $\mathrm{m}^{2}$. Se recuperaron restos de 44 individuos con diferente grado de completitud, en entierros individuales y múltiples, primarios y secundarios. Se han hallado miles de restos faunísticos de, por lo menos, 40 taxones diferentes, muchos de los cuales se encontraban asociados con cientos de instrumentos líticos, y miles de desechos de talla. En los niveles superiores se ha recuperado también material posthispánico como metal, vidrio, ladrillos y loza. Los valiosos hallazgos de AS2 incluyen información para entender el poblamiento americano y de la región pampeana. En 1998, se mudó la colección del sitio -que estaba depositada en el Museo de Ciencias Naturales de La Plata- al Departamento de Arqueología de la Facultad de Ciencias Sociales de la UNICEN (Olavarría). En la actualidad, el material recuperado durante los trabajos de campo de los aficionados está depositado en el Museo "José A. Mulazzi"

\footnotetext{
2. El Pleistoceno es una época geológica que comienza hace 2,59 millones de años, y su etapa final se sitúa aproximadamente 12.000 años antes del presente.

3. El Holoceno es la última y actual época geológica del período Cuaternario. Comprende los últimos 11.784 años.
}

de Tres Arroyos y los restantes materiales se encuentran en la Facultad de Ciencias Sociales de la ciudad de Olavarría (Gutiérrez 2004).

Por las características anteriormente mencionadas, el sitio AS2 ha sido considerado como un sitio de relevancia internacional para la arqueología. Sin embargo, suele suceder que lugares de importante valor científico pasen inadvertidos por la sociedad y aun por las comunidades más cercanas (Endere 2004; Chaparro et al. 2010). El caso de Tres Arroyos es, en este aspecto, particularmente interesante de analizar por las razones que se desarrollan a continuación.

\section{El Museo Mulazzi y la comunidad de Tres Arroyos}

El Museo fue creado por Decreto Municipal en el año 1979 con motivo de los importantes hallazgos de "Arroyo Seco", los que por entonces ya eran objeto de investigaciones sistemáticas por parte de la Universidad Nacional de La Plata. Poco después, el Comisionado Municipal Ángel A. Cortese cedió el edificio del ex Mercado San Martín para destinarlo a Museo, ya que inicialmente funcionaba en la sede del Grupo Boy Scout (Endere 2004). En el año 2005, se inauguró la exhibición arqueológica. Finalmente, en 2007, se presentó el primer sector de la reformulación de la Muestra Histórica (Conforti et al. 2007). Actualmente, el Museo Municipal José A. Mulazzi funciona en la ex sede del Mercado San Martín, ubicado en una de las avenidas principales de la ciudad de Tres Arroyos.

En el interior del museo, en la planta baja, se encuentran el sector administrativo, un salón de usos múltiples (en adelante, SUM) y la exhibición de arqueología, que se divide en tres sectores. En el primero de ellos, se incluye: "La Ciencia Arqueológica" y "Aborígenes Pampeanos", la primera consta de una introducción en la que se explican los principios básicos y la metodología de la arqueología; en la segunda parte se presenta una síntesis de la arqueología de la región pampeana. En el segundo sector, AS2, se narra la historia del sitio y los hallazgos más representativos con el propósito de mostrar un pasado profundo en el tiempo, en el que los cazadores-recolectores tenían un estilo de vida caracterizado por el nomadismo estacional que les permitía explotar diferentes recursos que se encontraban en la región. En esta cuestión, la muestra pretende corregir la tradicional visión de los pueblos indígenas -difundida por décadas en las escuelas- que afirma que ellos tenían una forma de vida simple y primitiva y que le asigna una escasa profundidad temporal a su ocupación en el territorio (Podgorny 1999). En la parte dedicada a los restos humanos de AS2, se proyecta un video explicativo (ver detalles más adelante). En el tercer sector, se describe la "Arqueología Argentina" (Figura 1).

También se halla una sala destinada a muestras itinerantes, una biblioteca, una sala de lectura y un patio con cuadrículas experimentales. A la muestra de arqueología no se accede directamente, sino que para recorrerla es necesario introducirse en un túnel que la contiene y que rodea el SUM en forma de herradura. En la planta alta se exhibe la muestra de historia local, que comprende desde la instalación de los primeros fortines hasta la actualidad. Dicha muestra es fácilmente visible desde 


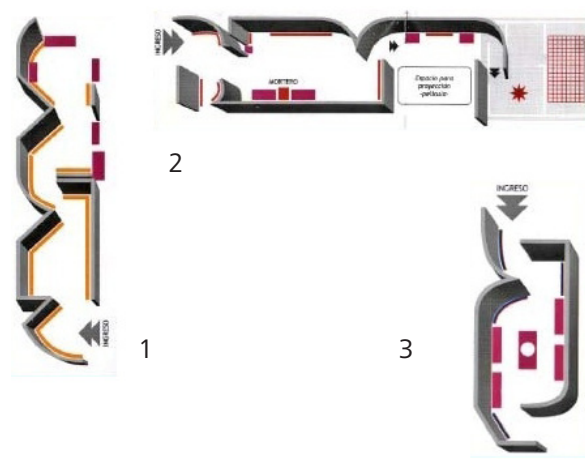

Figura 1. Planta de la distribución de la muestra permanente de arqueología. 1. Introducción a la Arqueología y Arqueología Pampeana. 2. Sitio arqueológico Arroyo Seco 2. 3. Arqueología en el territorio argentino.

Figure 1. Map of the permanent archaeological exhibition. 1. Introduction to Archaeology and Pampean Archaeology. 2. Arroyo Seco 2 archaeological site. 3. Archaeology in Argentina.

la planta baja, ya que también forma una suerte de herradura que rodea el SUM (Figura 2).

Es importante destacar que en la muestra de AS2 no se exhiben los restos humanos hallados en el sitio por decisión de los responsables de la exposición. Por dicha razón se presenta, en su reemplazo, el video titulado Tumbas sin tiempo, en el que se le explica al público las razones por las cuales no se exhiben restos humanos en el Museo (Conforti et al. 2007; Chaparro et al. 2010). Tumbas sin tiempo fue editado en 2005, y en sus trece minutos de duración se describen los hallazgos humanos de "Arroyo Seco", se explica su importancia científica y arqueológica, a la vez que se justifica la decisión de no exhibirlos debido al significado que tienen los restos de sus antepasados para los grupos indígenas (en general, sin especificar ninguno) 4 .

\footnotetext{
4. El reconocimiento de los derechos de los pueblos nativos en el mundo es ahora una realidad reconocida como un derecho humano básico (Conferencia Mundial de Derechos Humanos, Viena, 1993). En 1990, en el marco del Congreso Mundial de Arqueología, se firmó el Acuerdo de Vermillion entre arqueólogos e indígenas, que estableció lineamientos éticos sobre el tratamiento de restos humanos indígenas (Podgorny y Miotti 1994). En la Argentina, este movimiento se consolida a partir de una serie de sucesos tales como el reconocimiento de la preexistencia étnica y cultural de los pueblos indígenas argentinos establecido en la Constitución Nacional (1994); la sanción de la
}

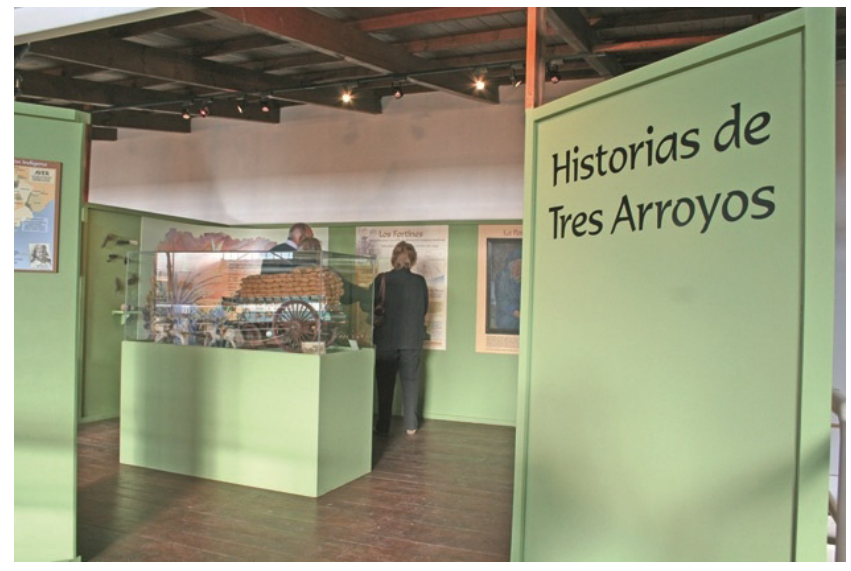

Figura 2. Sala con muestra permanente de la Historia Local.

Figure 2. Local History exhibition hall.
En dicho video se afirma que los grupos indígenas consideran una ofensa su exhibición en museos, y para ejemplificarlo se muestra una escena de un ritual realizado por descendientes indígenas del Noroeste Argentino en el Museo de La Plata frente a los restos humanos que allí se exhibían.

Cabe destacar que dichos rituales se realizaron antes de que se retiraran los restos humanos expuestos en el Museo de La Plata, proceso que inició en 2006 y culminó en 2007, y que enmarca también acciones de devolución de restos a las comunidades indígenas (Ametrano 2010). Asimismo, el video incluye el testimonio de un representante de pueblos originarios que califica de "indignante y dolorosa la exposición en una vitrina de lo más sagrado que tienen". Finalmente, se rescata que "lo que se ha investigado a partir de estos restos son doce mil años de historia extinguida por la conquista española, primero y la conquista del desierto, después". El video posee una estética muy cuidada en la que los testimonios están en voz en off y se muestran imágenes de archivo de excavaciones del sitio, así como del ritual realizado por los grupos indígenas en el Museo de La Plata y fragmentos de los paneles expuestos en la muestra del Museo Mulazzi. Sobre la decisión de no exhibir los restos humanos hallados en AS2, el director de las excavaciones sostiene que

"a partir de la década del noventa se hizo muy fuerte el reclamo de los pueblos indígenas de no exhibición de los restos, y hubo una movida a nivel mundial, por ejemplo, la firma del Acuerdo de Vermillion, entre los arqueólogos y los pueblos indígenas, en el marco del Congreso Mundial de Arqueología, que estableció un código de ética con relación al tratamiento de restos humanos indígenas, es decir que hubo un movimiento mundial de la arqueología que impactó en Argentina y también a nivel personal, entonces, cuando se decide armar el nuevo museo le propuse a Marisa hacer lo de la película y así quedó" (Gustavo Politis, com. pers., 2011).

\section{Antecedentes de los estudios de público}

Los estudios de las percepciones de los visitantes en relación con la presentación de un sitio arqueológico al público o de una exhibición de museo han sido sumamente utilizados, particularmente en el ámbito internacional (e.g., Merriman 1991; McManus 1991, 1998, 2000, etc.) y más recientemente a nivel nacional (Endere 2007; Assandri y Zabala 2010; Reca 2010). Con ellos se pretende tener una aproximación más directa y clara de la manera en que los visitantes interpretan la información que se les provee y, en consecuencia, contribuir a mejorar las estrategias para enfrentar los preconceptos que ellos puedan tener (McManus 1998). La mayoría de los estudios sobre el público en museos y exhibiciones tienen como objetivo central no sólo la evaluación de la muestra (Pérez Santos

Ley de Disposición de los Restos Mortales que Formen Parte de Museos y/o Colecciones Públicas o Privadas (Ley 25.517 del 2001) y el Primer Foro Pueblos Originarios/Arqueólogos, plasmado en la Declaración de Río Cuarto (2005), en la que se recomienda, en un marco de respeto mutuo, la no exhibición de restos humanos en los museos del país, así como la sensibilización del público sobre las razones que fundamentan dicha decisión, entre otras cuestiones (Pérez Gollán 2005). 


\begin{tabular}{|l|l|}
\hline 1) Sexo: Femenino - Masculino & 2) Edad \\
\hline 3) Ciudad en que vive & 4) Ocupación \\
\hline 5) Nivel Educativo & 6) Motivo de la vitata \\
\hline 7) ¿Cómo se enteró de la existen- & 8) ¿Cuál es su opinión sobre \\
cia de la muestra? & la muestra? \\
Por los medios de comunica- & Muy Buena: \\
ción: & Buena: \\
Por la escuela: & Regular: \\
Otro (especifique): & Mala: \\
\hline 9) ¿Hay algo que no le gustó? & 10) ¿Qué es lo que menos \\
& le gustó? \\
\hline 11) ¿Hay algo que le llamóla & 12) ¿Conocía la existencia de \\
atención? & sitios arqueológicos en Tres \\
& Arroyos? \\
& Sí: \\
& En caso afirmativo: ¿cómo se \\
& enteró de su existencia? \\
& Por los medios de comu- \\
& nicación: \\
& Por la escuela: \\
& Otro (especifique): \\
\hline 13) ¿A través de qué medio se & 14) ¿Cómo vivían los pri- \\
informa de lo que sucede en la & meros pobladores de Tres \\
ciudad? & Arroyos? \\
Radio: & \\
Internet: & \\
TV: & \\
Diarios: & \\
\hline 15) ¿Cómo le resultó la visita? & \\
Muy Buena: & \\
Buena: & \\
Regular: & \\
Mala: & \\
\hline
\end{tabular}

Tabla 1. Encuesta diseñada para los visitantes de la muestra arqueológica.

Table 1. Survey for visitors to the permanent archaeological exhibition.

2000), sino también el conocimiento y entendimiento de los públicos de museos (Murriello 2006). Desde esta perspectiva, se busca analizar, evaluar, entender, registrar e interpretar las características, los comportamientos, las motivaciones y las ganancias cognitivas y afectivas de los públicos que visitan los museos. Se considera que los museos son espacios de educación no formal (Prieto Castillo 1995) en los que debe analizarse tanto el momento de la visita como su impacto a largo plazo, valorizando el contexto personal, sociocultural y físico a lo largo del tiempo, a partir de un abordaje multidimensional de la experiencia del público (Vergo 1989; Laumonier 1993; Falk y Dierking 2000).

\section{Diseño metodológico}

Con el objetivo de conocer el público que visita la muestra de arqueología del Museo Mulazzi, así como también sus opiniones respecto de esta, se diseñó como instrumento una encuesta (Tabla 1) que permitiera tener una interacción directa con los visitantes. Estudios de este tipo son útiles para evaluar las fortalezas y debilidades de la exhibición, verificar qué funciona y qué no funciona en ella (Loomis 1987; Screven 1990; Pérez Santos 2000) y relacionar ese análisis con los objetivos de la educación no formal y la comunicación pública de la arqueología en el complejo proceso de puesta en valor del patrimonio arqueológico.
En relación con las técnicas de evaluación empleadas en los estudios de visitantes, la encuesta es aquella que permite relevar diversas variables, tales como las características sociodemográficas, descripción de comportamientos, precisión de las preferencias ante la exposición, satisfacción, identificación, entre otras (Hood 1981; Pérez Santos 2000). Si bien las encuestas podían implementarse de forma autoadministrada, se optó por alguien que seleccionara al visitante que la responda para evitar resultados sesgados. Es por ello que el presente muestreo fue administrado por el personal del Museo y aplicado a los asistentes que visitaron la muestra arqueológica con guía, en un lapso de tiempo limitado (tres meses).

De acuerdo con este enfoque metodológico, se diseñó un modelo de encuesta que combina preguntas cerradas y abiertas, dirigidas a todo tipo de público. En consecuencia, se encuestó a 172 visitantes del museo ${ }^{5}$.

\section{Resultados}

A partir de las encuestas efectuadas se observa que la mayor franja etárea de público (más de un 75\%) corresponde a visitantes de entre 10 y 20 años, y el porcentaje restante, casi en iguales cantidades, a personas de entre 20 y 40 años y de entre 40 y 62 años (Figura 3). La mayoría de los visitantes (77\%) son estudiantes, y el resto, en menor porcentaje, son docentes, empleados y jubilados (Figura 4). El 85\% de los visitantes procede de la ciudad de Tres Arroyos, lo que podría significar dos cuestiones: por un lado, una fuerte acción difusora del museo sobre los pobladores locales $y$, por otro, un bajo impacto sobre las visitas de otros lugares. Entre los otros lugares de residencia se destacan ciudades del conurbano bonaerense (Quilmes, Boulogne); también hay un mínimo de visitantes de Bahía Blanca, Necochea; de otras provincias (La Pampa) y del extranjero (Chile y España). El 60\% de los encuestados posee escolaridad básica; el $17 \%$, media; el $13 \%$, terciaria; y un 10\% cuenta con estudios universitarios. Esto podría fundamentarse en el hecho de que la mayoría de los encuestados forman parte de contingentes escolares. Un dato que se debe tener en cuenta es cómo se enteraron de la existencia de la muestra. La mayoría (60\%) lo hizo a través de la escuela; en segundo lugar, por motivación personal; y finalmente, a través de la difusión en los medios de comunicación tresarroyenses.

Conforme con estudios de visitantes efectuados a nivel internacional (McManus 1991), las referencias de familiares y amigos es considerada la motivación más común por la cual la gente visita museos o centros de patrimonio. Sin embargo, lo interesante de destacar aquí es que la escuela (en sus diferentes niveles de enseñanza) aparece como la principal difusora de la exhibición del sitio a nivel local.

De este cuestionario se deduce también que la percepción

\footnotetext{
5 . Cabe aclarar que los resultados de este relevamiento, si bien no pretenden proveer una muestra estadísticamente representativa, aportan indicadores cualitativos respecto de ciertas tendencias generales que son importantes para entender los complejos procesos de comunicación involucrados.
} 


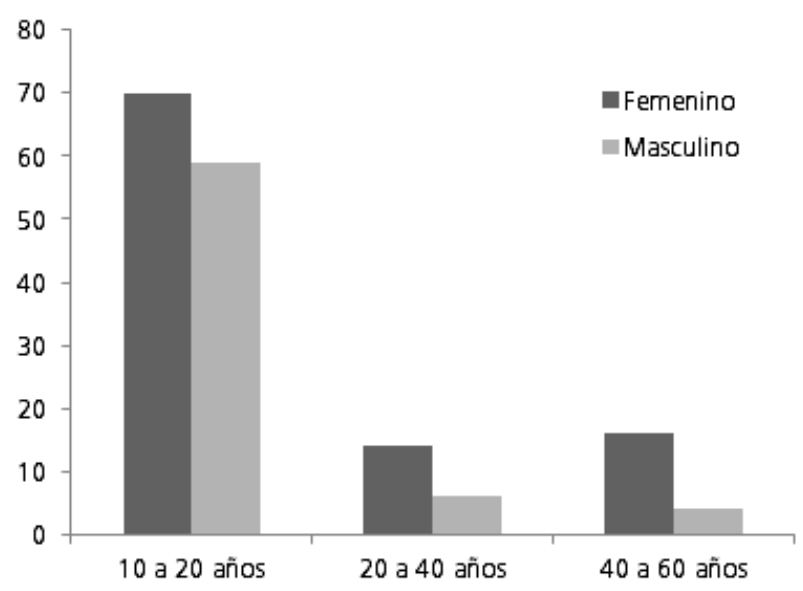

Figura 3. Resultados de la encuesta: edad.

Figure 3. Survey results: age

general que se llevan los visitantes de la muestra es positiva. La gran mayoría utiliza calificativos altamente elogiosos y entusiastas. Sobre este aspecto se decidió repreguntar, ya que, ante la pregunta sobre si hay algo que no les gustó, no mencionan aspectos que no les hayan gustado $y$, a la pregunta sobre qué fue lo que menos les gustó, la mayoría responde "nada", descartando los aspectos negativos. Sin embargo, en el caso de esta última pregunta, un $6 \%$ incluye entre los temas que "no les gustaron" el video, la visita guiada, las armas, los esqueletos de "los indios" (se entiende por esto las imágenes expuestas tanto en la gráfica como en el video, ya que, como hemos señalado, no hay restos humanos expuestos), las fotos y los mapas. En este caso, la repregunta sirvió para insistir sobre cuestiones negativas, ya que el público tiende a ser complaciente o poco crítico en sus respuestas.

En relación con la pregunta sobre si algo le llamó la atención, las respuestas más frecuentes refieren a la exhibición del video (62 respuestas), le sigue la muestra arqueológica (23 respuestas), el gliptodonte (21 respuestas), 39 de ellos se refieren a temas variados y 27 no responden. Entre los temas variados, los que más se reiteran son: la información (siete respuestas), la presentación (seis respuestas), el toxodon (cinco respuestas), las armas (cinco respuestas), los fósiles (cuatro respuestas) y los restos de animales extintos (cuatro respuestas). Desde las estrategias comunicativas y de exposición de la muestra, la inclusión del video en reemplazo de la exhibición de restos humanos es algo no convencional y se refleja en el hecho de que a la mayoría parece ser lo que más le llamó la atención (que no es lo mismo que nos les haya gustado). Esto se relaciona con el "factor sorpresa", algo inesperado que los saca del guión tradicional y es, claramente, un recurso didáctico que se debe tener en cuenta para captar la atención del visitante. Un aspecto destacable es el conocimiento del sitio que tenían los visitantes en forma previa a la visita. En este caso, es importante resaltar que el $70 \%$ conocía la existencia del sitio. Al preguntarles cómo se enteraron de su existencia, el mayor porcentaje señala que lo hizo por la escuela, y el resto, por los medios de comunicación local, aunque vale la pena resaltar que un alto porcentaje (24\%) no respondió la pregunta. En relación con ello, también se les preguntó de qué modo se informan sobre lo que sucede

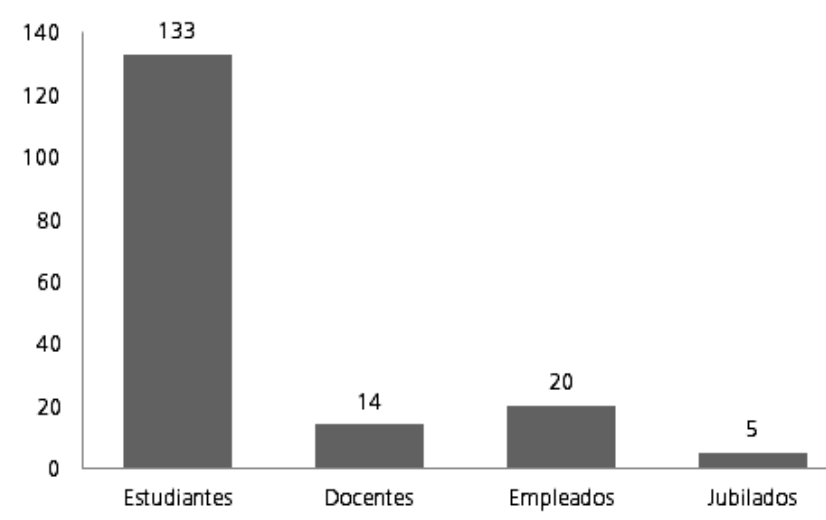

Figura 4. Resultados de la encuesta: ocupación.

Figure 4. Surveyresults: occupation.

en la ciudad. La mayoría (28\%) afirmó hacerlo a través de Internet. Cabe destacar que la mayor parte de ellos reconoce informarse por más de uno de estos medios de comunicación. Un aspecto muy interesante es que, finalizada la encuesta, se les pide que sinteticen cómo vivían los primeros pobladores de Tres Arroyos, a partir de un interrogante abierto. Lo sorpresivo es que la mayoría de ellos no responde o indica no saberlo y, quienes lo hacen, responden de manera equivocada, recién el tercer lugar lo ocupa una respuesta que puede considerarse correcta en cuanto a la especificidad del contenido (Figura 5), que es la que indica que vivían como nómades. En las otras dos respuestas masivas, pero erróneas, marcan que: a) vivían en situación de pobreza, asimilándolo con la idea de que eran atrasados o primitivos, cuestión que se ve reforzada en los discursos escolares (Podgorny 1999); y b) ubicarlos en fortines, lo que indican que confunden la escala temporal y el período de la historia, ya que los fortines se vinculan con la llegada del "hombre blanco" a la región en el siglo XIX y no con los primeros grupos de cazadores-recolectores que habitaron AS2 12.000 años atrás. La última opción de la encuesta se refiere a comentarios y, en ella, la mayoría agradecen la visita, que es considerada instructiva. El deseo de todos es que el museo siga creciendo.

No se registran pedidos ni críticas, excepto por una mayor cantidad de sillas en la sala de video y una mayor difusión al espacio de recreación y lectura que posee el museo. Esta crítica sobre la sala de video podría explicar, en parte, por qué el video fue uno de los aspectos de la muestra que no les gustó a algunos visitantes. Es decir que el hecho de tener que ver un video durante casi 15 minutos parados o sentados incómodos en el piso podría convertirse en una experiencia desagradable para los visitantes.

\section{Discusión}

Cabe destacar que en este trabajo, las opiniones del público, no son sólo analizadas en términos de nivel de conocimiento o exactitud en relación con la información científica, sino también con el objetivo de identificar las diferentes percepciones y opiniones respecto del proceso de valoración de dicho patrimonio. Esto supone partir de analizar cómo el museo y el sitio son parte de una comunicación, de un circuito y de 
un proceso de intercambio con otras instituciones, personas y grupos de la comunidad, ya que lo comunicacional está integrado a la complejidad misma de lo social (Uranga 2007). Así, el foco no se centra sólo en el mensaje que el museo transmite sobre el sitio, sino en la interacción entre los significados otorgados por ambos (museo y sitio) y aquellos atribuidos por el público en una relación de participación recíproca y dialógica con su entorno (Cury 1999, 2005).

Este diálogo se hace desde un enfoque comunicacional holístico en el cual dicha exposición, además de ser considerada espacio de comunicación en sí misma, precisa ser analizada en el contexto de la institución como un todo (Hooper Greenhill 1998).

En general, este testeo de las opiniones del público respecto de la exposición de arqueología AS2 en el Museo Mulazzi permite identificar algunas tendencias que dan cuenta, en primer lugar, de la fuerte relación que se ha establecido entre el museo y los diferentes niveles de la educación formal en Tres Arroyos. Esto es particularmente significativo si se considera al Museo como espacio de educación no formal (Prieto Castillo 1995; Pérez Santos 2000). En este contexto, la comunicación constituye, para los museos, una alternativa para diseñar nuevas formas estratégicas de aprendizaje, difusión y transferencia del patrimonio arqueológico, en el complejo proceso de construcción social del conocimiento.

El estudio previo realizado en el año 2004 por Endere aborda la relación del sitio AS2 con la comunidad de Tres Arroyos, previo al montaje de la muestra permanente en la sede del ex Mercado. Algunos de los aspectos más sobresalientes de esa investigación se retoman en este trabajo para discutir qué rol ha venido a cumplir la muestra en relación con la comunicación pública del sitio. Por ejemplo, una de las cuestiones que surgían como centrales, previa a la exhibición, era la incertidumbre del público sobre el destino de los materiales. Aún hoy, este aspecto continúa latente y sigue siendo central, a pesar de que la muestra ya tiene seis años de vigencia.

Esta exhibición está montada de manera gráfica, dado que prevalecen en ella las imágenes y las representaciones por sobre los materiales originales (Figuras 6 y 7), en consonancia con las nuevas tendencias de exposición en museos a nivel mundial, a lo que se suma el hecho de que el museo no expone los restos humanos (Figuras 8 y 9). Frente a esta situación, el público continúa con una actitud de asombro (frente al factor sorpresa que significan los recursos museográficos que reemplazan los materiales) y de reclamo (ante la curiosidad que despierta la ausencia, principalmente, de restos humanos), y pareciera que esta cuestión quedara inconclusa, no porque la comunidad no respete la decisión de no exponerlos, sino porque quisiera saber dónde y cómo están guardados.

Esto podría, en parte, relacionarse con la tendencia que Moreno Guzmán (2001) define como el "encanto y desencanto del público", al no encontrar en su mayoría piezas originales y hallar, en su reemplazo, representaciones gráficas y/o audiovisuales en el discurso museográfico, lo que se traduce en un problema

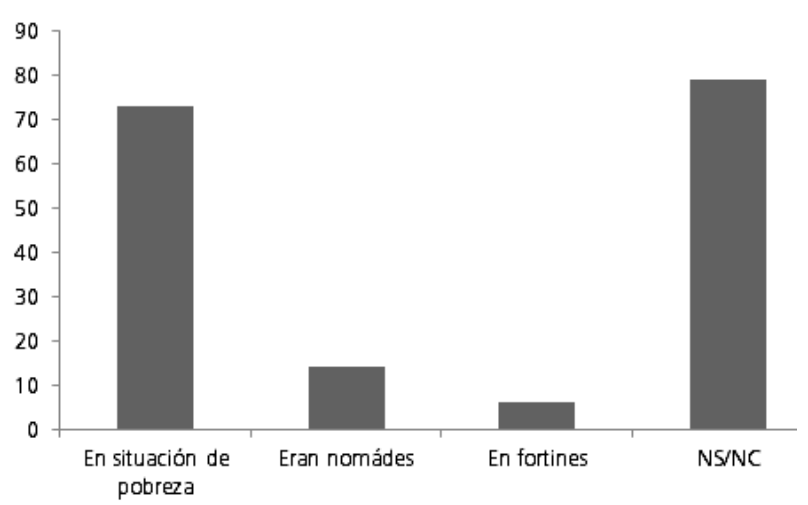

Figura 5. Resultados de la encuesta: síntesis de conocimiento sobre modo de vida de los primeros habitantes de Tres Arroyos.

Figure 5. Survey results: knowledge of the ways of life of the first Tres Arroyos settlers.

de legitimación de la muestra. Las encuestas refuerzan este supuesto cuando el público ubica al video entre aquello que menos le gustó o como una de las cosas que más les llamó la atención.

Puede observarse además que continúa vigente el quiebre que ya planteaba Endere (2004) en su trabajo, cuando sostenía que la identidad de los habitantes de Tres Arroyos está más ligada a la gesta de los colonos holandeses y daneses que al pasado de los grupos humanos que habitaron la región hace miles de años. Este hecho puntual estaría poniendo de manifiesto cómo los actores se apropian diferencialmente de su patrimonio cultural. La muestra, el sitio y su profundidad histórica están siendo asimilados por la comunidad en tanto patrimonio público por la importancia y el reconocimiento científico que este posee.

Podría afirmarse que el problema radica en la importancia de la memoria en tanto construcción colectiva, que incluye un ordenamiento de acontecimientos e interpretaciones del pasado que se quiere salvaguardar para reforzar sentimientos de pertenencia en el presente (Pollak 2006). La memoria, a lo largo de la historia, proporciona marcos y puntos de referencia que mantienen la cohesión de los grupos que no pueden encontrarse en la prehistoria. La memoria está constituida por personas, personajes (los primeros inmigrantes) y lugares (puntos de salida y de destino) que son seleccionados. No todo queda registrado en ella. La memoria es un elemento constituyente del sentimiento de identidad y, por ende, es un componente importante del sentimiento de continuidad y coherencia. Ahora bien, no hay forma de remitir a recuerdos o modos de vida de la época de la que da cuenta el sitio.

Los tresarroyenses pueden conocer ese pasado a partir del sitio y de la muestra, y por ende, valorarlo; sin embargo, para la identificación hay procesos más complejos y "vividos" para los que estos recursos no bastan.

Las expectativas que generaba la propuesta de museo antes de su concreción eran, en términos generales, que cumpliera una función "popularizadora" y que deje de considerarse a "Arroyo Seco" como propiedad exclusiva de los científicos y entusiastas locales. Dado el resultado positivo de las encuestas 


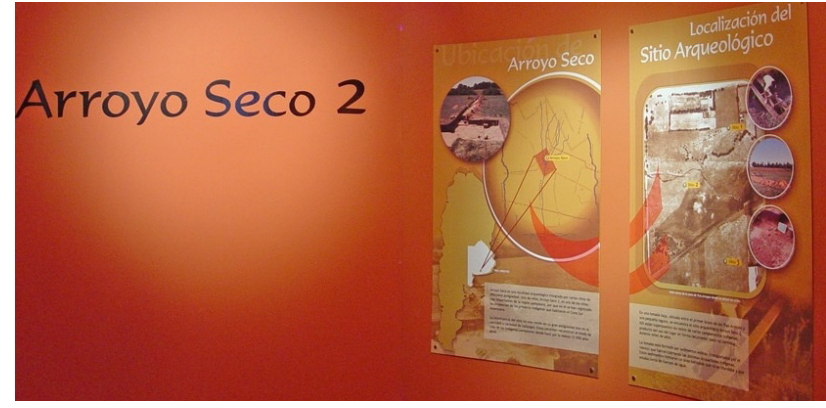

Figura 6. Material gráfico que compone la muestra. El sitio Arroyo Seco 2.

Figure 6. Visual support of the exhibition: Introduction to Arroyo Seco 2 site.

sobre la muestra en el museo, podría afirmarse que, en parte, esas expectativas fueron alcanzadas. El hecho de que la mayoría de las visitas sean escolares y que los encuestados conozcan la existencia de la muestra por su tratamiento en la escuela permite afirmar que, como espacio educativo, el museo cumple la función de articular los conocimientos incluidos en la currícula escolar, complementando con aquellos que refuerzan la identidad local a partir de la educación patrimonial. Cabe recordar que esta pretende despertar la inquietud por conocer el patrimonio, no sólo en los especialistas, sino en todos los ciudadanos (Fabra et al. 2007). Esta es la función educativa que viene a cumplir la muestra de AS2. Sin embargo, no se puede dejar de reconocer el sesgo de "público cautivo" que representan las visitas escolares frente al amplio público. Hay una importante franja etárea que está escasa o nulamente representada en esta muestra (adultos mayores de 20 años). Esta situación se contradice con una de las características centrales de la educación no formal, que es la amplitud de edades que incluye entre su público, que no se limita tan sólo a los escolares. A pesar de la importante acción educativa que

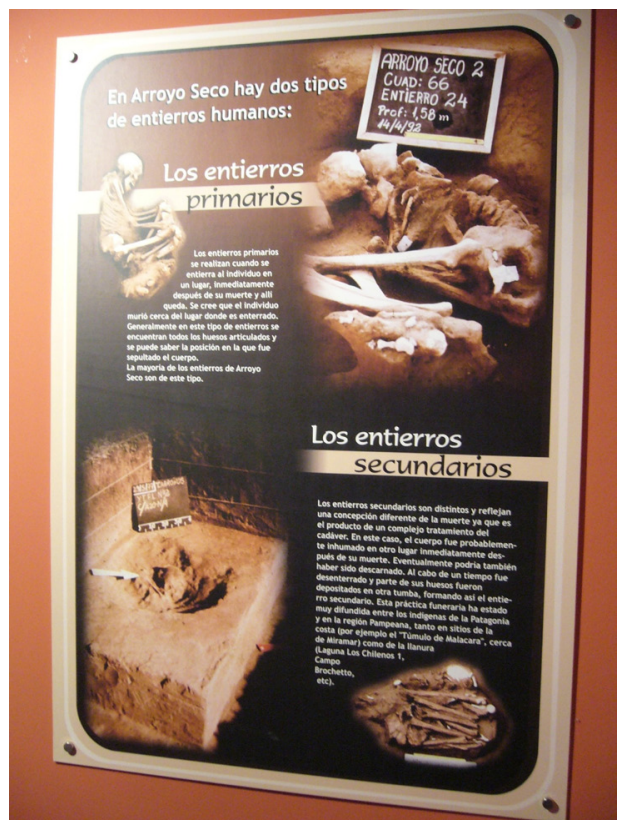

Figura 8. Presentación de los hallazgos en Arroyo Seco 2.

Figure 8. Representation of Arroyo Seco 2 findings.

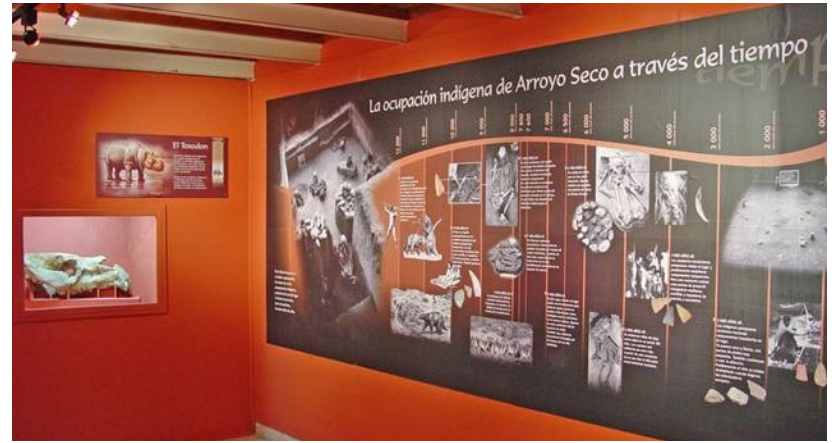

Figura 7. Cronología del sitio

Figure 7. Site chronology.

cumple el museo en la comunidad, parece que aún continúa siendo un desafío atraer otros públicos e interesar a visitantes de otras edades, ocupaciones y procedencias. Esta percepción quedaría representada en las encuestas en el bajo porcentaje de visitantes que no residen en Tres Arroyos y se encuentran de visita en la ciudad, como así también en la escasa porción de esos visitantes que se acercan a la muestra como parte de una actividad turística o vacacional.

Otro aspecto que puede destacarse, del análisis de las encuestas, es que los medios de comunicación son un referente fuerte para los visitantes de diferentes edades (incluida la escolar) en relación con el museo y las investigaciones arqueológicas. En este sentido, puede afirmarse que es sumamente importante el rol que desempeñan los medios en el vínculo que se establece entre arqueología y sociedad. Que la prensa local o regional considere el valor social de este tipo de conocimiento y lo retransmita a la sociedad para que esta pueda, además de conocerlos, apropiárselos, potencia la capacidad de interesar al público lector en temas científicos de impacto social y cultural, y contribuye a desmitificar las ciencias y a acortar las distancias que las alejan del público. Este es un aspecto en el que coinciden todos los entrevistados, y lo resaltan en términos muy positivos.

Sin embargo, la existencia de un vínculo estrecho entre museo y comunidad no necesariamente garantiza que el mensaje emitido desde el museo sea adecuadamente recepcionado por sus visitantes y por la comunidad en general. Ello es particularmente evidente cuando se abordan temáticas relativas al pasado

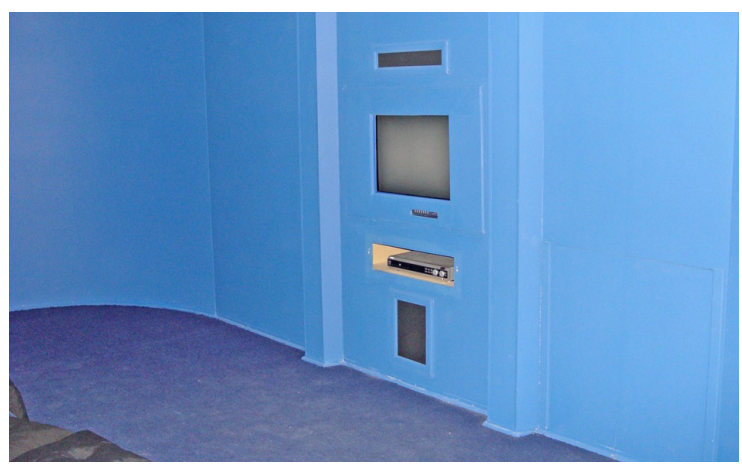

Figura 9. Equipamiento para el soporte audiovisual

Figure 9. Equipment dedicated to audiovisual support. 
prehispánico, ya que la concepción general de nuestra sociedad respecto de "los indios" suele estar viciada de preconceptos y valoraciones negativas. Identificarlas resulta vital en pos de pensar mejores estrategias para plantear la muestra, focalizar las visitas guiadas y diseñar actividades especiales, dedicadas a asegurar una adecuada transferencia de los conocimientos científicos a la comunidad. Cabe destacar que reflejo de ello pueden ser las respuestas recibidas ante la única pregunta (abierta) sobre la interpretación del contenido general de la muestra. Al tener que completar la consigna sobre "cómo vivían los primeros pobladores de Tres Arroyos", la mayoría de los encuestados que responden coinciden en indicar que vivían en situación de pobreza (Gráfico №3). Este concepto de "pobreza" es un estereotipo actual que poco o nada tiene que ver con el modo de vida de aquellos grupos indígenas. Ahora, lo que debe replantearse es qué es lo que está fallando para que se produzcan estas interpretaciones erróneas. Si bien la encuesta no tiene valor estadístico, marca una tendencia. Quizás la visita guiada sea insuficiente para superar prejuicios y, en ese caso, sería necesario explorar estrategias comunicacionales para dar un mensaje más claro y contundente. Para ello se debería, en un futuro, reforzar la visita guiada y realizar luego un nuevo muestreo.

Lo que podría efectuarse, además, es un análisis de la distribución del espacio del Museo Mulazzi en relación con la disposición de las muestras. Teniendo en cuenta que "el espacio habla" (Hall 1989), podría afirmarse que estaría faltando la conexión espacial entre el pasado indígena y el presente con respecto a la población de Tres Arroyos. Tal vez el hecho de que la muestra arqueológica esté aislada dentro de una especie de "túnel (del tiempo)" del resto de los procesos históricos (visibles a simple vista) que derivaron en la actual conformación de la ciudad, contribuya a desconectar el pasado del presente, como si el relato completo del museo no estuviera integrando la historia local, desde la más profunda hasta la más reciente. Si relacionamos esto con la idea de que tanto el pasado como lo que consideramos patrimonio constituyen una construcción social, gran parte de esa construcción estará sujeta a la manera en que es narrada y presentada, no sólo desde el discurso científico (en este caso, arqueológico), sino también desde el contexto espacial en el cual está inserto. En efecto, las investigaciones sobre la manera en que se transmite el saber de cada sociedad por medio de las escuelas y los museos demuestran que diversos grupos se apropian en formas diferentes y desiguales de la herencia cultural. No basta que los museos estén abiertos a todos, que sean gratuitos y promuevan en todas las capas de la sociedad su acción difusora, se debe tener en cuenta que la reformulación del patrimonio, en términos de capital cultural, tiene la ventaja de no presentarlo como un conjunto de bienes estables, neutros, con valores y sentidos fijos, sino como un proceso social que, como el otro capital, se acumula, se renueva, produce rendimientos que los diversos sectores se apropian en forma desigual (García Canclini 1999). Por ello es importante que las estrategias de comunicación sean integrales y atiendan a la diversidad de públicos que visitan el museo, como así también que tiendan a la inclusión de otros sectores de la población a los que aún no accede (Merriman 2000).

\section{Comentarios finales}

En síntesis, la muestra de arqueología en el Museo Mulazzi viene a cumplir una etapa ineludible en el vínculo que une, desde la década de 1970, a la investigación arqueológica con la comunidad local, al brindar "una respuesta institucional permanente, más completa e intelectualmente más accesible al público que el sitio mismo y sus esporádicas investigaciones de campo" (Endere 2004: 464). En ese contexto, los estudios de visitantes pretenden contribuir a consolidar esa relación, construyendo puentes aún más sólidos entre arqueología, museo y comunidad en Tres Arroyos. Sin embargo, cabe destacar que estas investigaciones no completan el análisis, sino que sólo proveen una aproximación respecto de las opiniones generales del público, y en consecuencia es preciso, en el futuro, profundizar -complementando con otras técnicas- el conocimiento sobre cómo ese pasado es apropiado por la comunidad local y resignificado en tanto patrimonio cultural.

Olavarría, 16 de mayo 2012

\section{Agradecimientos}

A Diana Martín, Directora del Museo Mulazzi y a su equipo de trabajo por la colaboración prestada durante el trabajo de campo en la ciudad de Tres Arroyos. Al Dr. Gustavo Politis por ceder gentilmente su testimonio y aportar datos de AS2 y del Museo Mulazzi. A las Dras. María Luz Endere y María Gabriela Chaparro por sus valiosos aportes de lectura y correcciones. A los evaluadores que ayudaron a mejorar la calidad de este artículo. Este trabajo presenta parte del desarrollo de la investigación doctoral de la autora titulada: "El rol de la comunicación pública de la arqueología y la educación no formal en la valoración social del patrimonio arqueológico en la provincia de Buenos Aires, Argentina" (UNQuilmes), en el marco de la beca de postgrado tipo II (CONICET). A su vez, es producto de investigaciones desarrolladas en el seno de PATRIMONIA (Programa de Estudios Interdisciplinarios de Patrimonio) del INCUAPA (Investigaciones Arqueológicas y Paleontológicas del Cuaternario Pampeano), Facultad de Ciencias Sociales, UNICEN y fueron financiados por la ANPCyT para el Proyecto: "Investigación y Manejo del Patrimonio Arqueológico y Paleontológico en el Área Interserrana Bonaerense" (PICT 200701563), dirigido por María Luz Endere.

\section{Bibliografía}

Acosta, A., Cruz, I., Curtoni, R., Fernández, P., Lazzari, M., Olivera, D. y J. Radovich 1996. Gente de la Tierra. Una experiencia de divulgación científica. En S. Alderoqui, (Comp.), Museos y Escuelas. Socios para educar, pp. 125-144. Paidós, Buenos Aires.

Ametrano, S. 2010. Historia de una restitución. Revista Museo 3(21): 61-67.

Assandri, S. y Zabala, M. 2010. Aproximaciones a las visitas familiares en el contexto del Museo de Antropología. En Holguin, M.; Baquero Martín, M.; Botero Saltaren, M., (Comp.), Educar: aprender y compartir en museos, pp. 242-253. Teseo y CECA, Buenos Aires. 
Barrientos, G. 1997. "Nutrición y dieta de las poblaciones aborígenes prehispánicas del sudeste de la región pampeana". Facultad de Ciencias Naturales y Museo. Universidad Nacional de La Plata, Argentina. Tesis de Doctorado. Universidad de La Plata.

Barrientos, G., I. Pérez. 2002. La dinámica del poblamiento humano del Sudeste de la Región Pampeana durante el Holoceno. Intersecciones en Antropología 3: 41-54.

Chaparro, M., Conforti, M., Mariano, M. y Endere, M. 2010. Representaciones Identitarias en Museos del Centro de la Provincia de Buenos Aires, Argentina. Actas del 1er Congreso Iberoamericano sobre Patrimonio Cultural: Experiencias metodológicas en el conocimiento del patrimonio, Costa Rica.

Cofré, B. 2003. Técnicas e instrumentos para la recolección de información cualitativa. En A. Carraso y B. Cofré (Eds.), Conozcamos juntos la historia y cultura de nuestra región, pp. 209-216, Tarapacá, Chile.

Conforti, M., Endere, M. y Martín, D. 2007. El Patrimonio Arqueológico en relación a la educación no formal, la comunicación y la exhibición. El caso del Museo Municipal 'José A. Mulazzi' de la ciudad de Tres Arroyos, Provincia de Buenos Aires, ponencia presentada en las Quintas Jornadas Técnicas sobre: Conservación, Exhibición y Extensión Educativa en Museos. Río Cuarto, Córdoba.

Cooper, M., Firth, A., Carman, J. y Wheatley, D. (Eds.) (1995). Managing Archaeology, Routledge, Londres.

Cortegosso, V. y Chiavazza, H. 2003. Teoría y Práctica Arqueológica: Concepciones del pasado y sociedad en Mendoza, Argentina. En R. Curtoni y M. Endere (Eds.), Análisis, interpretación y gestión en la Arqueología de Sudamérica, pp. 251-276. UNICEN, Olavarría.

Cury, M. 1999. Exposiçaõ: análise metodológica do processo de concepção, montagem e avaliação, Escola de Comunicações e Artes, Universidade de São Paulo.

Cury, M. 2005. "Comunicação museológica: uma perspectiva teórica e metodológica de recepção". Escola de Comunicações e Artes. Universidade de São Paulo, Brasil. Tesis de Doutorado. Universidade de São Paulo.

ICOMOS 2004. Carta de ENAME para la interpretación de lugares pertenecientes al patrimonio cultural, ICOMOS, Venecia.

Endere, M. 2004. Arqueología, Patrimonio y Comunidad local. El caso de Arroyo Seco 2, Partido de Tres Arroyos, Provincia de Buenos Aires. En G. Martínez, M. Gutiérrez, R. Curtoni, M. Berón y G. Madrid (Eds.), Aproximaciones arqueológicas pampeanas. Teoría, métodos y casos de aplicación contemporáneos, pp. 451-468, UNICEN, Olavarría.

Endere, M. 2007. Management of archaeological sites and the public in Argentina. BAR International Series 1708, Oxford.
Fabra, M., Roura Galtes, I. y Zabala, M. 2007. Reconocer, recuperar, proteger, valorar: prácticas de arqueología pública en Córdoba, ponencia presentada en el XVI Congreso Nacional de Arqueología Argentina. Jujuy.

Falk, J. y Dierking, L. 2000. Learning from museums. Visitors, experiences and the making of meaning. Altamira Press, Reino Unido

Ferraro, L. 2000. Sitios arqueológicos, uso público y sustentabilidad: el Valle de las Pinturas en el Parque Nacional Lihué Calel (Provincia de La Pampa), Quintas Jornadas de Jóvenes Investigadores del Instituto Nacional de Antropología y Pensamiento Latinoamericano. Buenos Aires.

Fidalgo, F., Meo Guzmán, L., Politis, G., Salemme, M. y Tonni, E. 1986. Investigaciones arqueológicas en el sitio Arroyo Seco 2 (Pdo. de Tres Arroyos, Pcia. de Buenos Aires, República Argentina). En A. Bryan (Ed.), New Evidences of the Peopling of the New World, pp. 221-270, Center for the study of Early Man, Mayne.

García Canclini, N. 1999. Los usos sociales del patrimonio cultural. En E. Aguilar Criado (Ed.), Patrimonio etnológico, nuevas perspectivas de estudio, pp. 16-33, Consejería de la Cultura, Junta de Andalucía, Andalucía.

Gómez, G., J. Prado, y M. Alberti. 1999. Micromamíferos del sitio Arroyo Seco 2 (provincia de Buenos Aires, Argentina). Sus implicaciones tafonómicas y paleoambientales. Estudios geológicos 55 (5-6): 273-281.

Gutiérrez, M. 2004. "Análisis tafonómicos en el área Interserrana (provincia de Buenos Aires)". Universidad Nacional de La Plata, Argentina. Tesis de Doctorado. Universidad de La Plata.

Hall, E. 1989. El espacio habla, Alianza, Madrid.

Hewison, R. 1987. The Heritage Industry, Methuen, Londres.

Hood, M. 1981. "Adult attitudes toward leisure choices in relation to museum participation". Ohio State University, USA. Tesis de Doctorado. Ohio State University.

Hooper Greenhill, E. 1998. Los museos y sus visitantes, Trea, Gijón.

Laumonier, I. 1993. Museo y Sociedad. Los Fundamentos de las Ciencias del Hombre, Centro Editor de América Latina, Buenos Aires.

Loomis, R. 1987. Museum visitor evaluation: New tool for management, American Association for State and Local History, Nashville.

McManus, P. 1991. Towards understanding the needs of museum visitors. En G. Lord (Ed.), The Manual of Museum Planning, pp. 35-52, HMSO, Londres. 
McManus, P. 1998. Finding out what the public knows and what they would like to know. The Museum Archaeologist 24: 10-13.

McManus, P. 2000. Archaeological display and the public. Museology and Interpretation, Archetype Publications, Londres.

Merriman, N. 1991. Beyond the Glass Case: The Past, the Heritage and the Public in Britain. Leicester Press, Leicester.

Merriman, N. 2000. Beyond the Glass Case: the past, the heritage and the public, Institute of Archaeology, University College London, Londres.

Moreno Guzmán, M. 2001. Encanto y desencanto. El público ante las reproducciones en los museos, Obra diversa, México DF.

Murriello, S. 2006. "As exibições e seus públicos: a Paleontologia no Museu de La Plata". Universidade Estadual de Campinas (UNICAMP), Brasil. Tesis de Doctorado. Universidade Estadual de Campinas.

Pérez Santos, E. 2000. Estudios de visitantes en museos. Metodología y aplicaciones. Trea, España.

Pérez Gollán, J. 2005. Comentario. Declaración de Río Cuarto. 2005. Primer Foro Pueblos Originarios - Arqueólogos. Río Cuarto, Argentina, Mayo 2005. Revista de Arqueología Suramericana 1(2): 290-203.

Podgorny, I. 1999. Arqueología de la Educación. Textos, indicios, monumentos. La imagen de los indios en el mundo escolar, Sociedad Argentina de Antropología, Buenos Aires.

Podgorny, I., L. Miotti. 1994. El pasado como campo de batalla. Ciencia Hoy 5(5):16-19.

Politis, G. 1984. "Arqueología del Área Interserrana Bonaerense". Facultad de Ciencias Naturales y Museo, Universidad Nacional de La Plata, Argentina. Tesis de Doctorado. Universidad Nacional de La Plata.

Politis, G. 1988. Paradigmas, modelos y métodos en la arqueología de la Pampa Bonaerense. En H. Yacobaccio (Ed.), Arqueología Contemporánea Argentina. Actualidades y Perspectivas, pp. 59-108, Ediciones Búsqueda, Buenos Aires.

Politis, G y Madrid, P. 2001. Arqueología Pampeana: estado actual y perspectivas. En E. Berberián y A. Nielsen (Ed.), Historia Argentina Prehispánica, pp. 737-814. Ediciones Brujas, Córdoba.

Politis, G., P. Madrid y G. Barrientos. 1992. Informe de la campaña 1992 al sitio Arroyo Seco 2 (Pdo. de Tres Arroyos, Pcia. de Buenos Aires, Argentina). Palimpsesto 1: 80-85.

Politis, G., P. Madrid y F. Oliva. 1988. Recientes hallazgos arqueológicos en el sitio 2 de Arroyo Seco (Pdo. de Tres Arroyos, Provincia de Buenos Aires). Novedades del Museo de La Plata 1 (12): 98-99.

Politis, G., E. Ton y F. Fidalgo. 1987. Man and Plesitocene megamammals in the Argentine Pampa: site 2 at Arroyo Seco. Current Research in Pleistocene Studies 4: 159-162.

Pollak M. 2006. Memoria, Olvido, Silencio. La producción social de identidades frente a situaciones límites. Ediciones Al Margen, La Plata.

Prieto Castillo, D. 1995. Educar con sentido. Apuntes para el aprendizaje, Ediciones Novedades Educativas, Buenos Aires.

Reca, M. 2010. El aporte de la semiótica al estudio de público a museo. Su aplicación en la sala etnografía del Museo de La Plata, trabajo presentado en el Primer Congreso Nacional de Museos Universitarios. La Plata.

Screven, C. 1990. Uses of evaluation before, during and after exhibit design, ILVS Review. Journal of Visitor Behaviour 1(2): 36-66.

Stone, P. 1989. Interpretations and uses of the past in modern Britain and europe. Why are people interested in the past? Do the experts know or care? A plea for further study. En R. Lyton (Ed.), Who needs the past?, pp. 195-206, Unwin, Londres.

Tapia, A. 1998. Patrimonio Arqueológico Local: Uso Social, Legislación y Globalización. Baradero, Provincia de Buenos Aires, trabajo presentado en las primeras Jornadas de Arqueología Histórica de la ciudad y la Provincia de Buenos Aires. Bernal.

Tedesco, J. 2004. Nas cercanías da memoria. Temporalidades; experiencia e narracao, UPFUCS, Brasil.

Uranga, W. 2007. Prospectiva estratégica desde la comunicación. Cátedras Sociales, http//: catedras.fsoc.uba.ar/uranga/ prospectiva_comunicacion_mayo_08.doc (Última consulta: 10/8/2011)

Vergo, P. (Ed.) 1989. The new museology, Reaktion Books, Wiltshire.

Walsh, K. 1992. The Representation of the Past: Museum and Heritage in the Post-Modern World, Routledge, Londres. 